CASE REPORT

\title{
Pilonidal sinus of the penis
}

\author{
$\mathrm{H} \mathrm{Al} \mathrm{Chalabi}$ \\ H A Ghalib \\ M Nabri \\ T O’Hanrahan
}

General Surgery Department, Sligo General Hospital, The Mall, Sligo, Dublin, Ireland

Correspondence: Hasan Al Chalabi 402 D The Glen, Aiken's Village, Sandyford, Dublin 18, Ireland.

Tel +35 3877438546 .

Email hasan_chalabi@hotmail.com
Abstract: Pilonidal sinus is a well recognised chronic inflammatory condition which commonly affects the natal cleft and finger web space. Pilonidal sinus of the penis is a rare clinical entity; few cases have been reported previously. The treatment strategy is almost the same as treating any pilonidal sinus and involves total excision of the sinus. Our diagnosis was established on the histopathological findings rather than a clinical-based diagnosis, Follow-up is advisable since the recurrence rate is high. Our case report is one of few cases reported on pilonidal sinus all over the world. Our patient had total excision of the sinus with complete recovery.

Keywords: pilonidal sinus, penile pilonidal sinus, chronic penile diseases

\section{Introduction}

Pilonidal sinus is a well recognized chronic inflammatory condition which affects the natal cleft, finger web space, and it is rare in the penis. We report on a case of penile pilonidal sinus in a 24-year-old man who has severe mental illness, autism, and developmental delay. The literature was reviewed and there were a few cases reported worldwide (Val-Bernal et al 1999; Chikkamuniyappa et al 2004; Kalsi et al 2004; O'Kane et al 2004).

\section{Case report}

A 24-year-old man who is known to have severe mental illness, autism, and a learning disability, presented with more than a one year history of recurrent ulcerative lesion on the middle of the dorsum of his penile shaft, intermittent erythema, and swelling. Despite several courses of antibiotics prescribed by his local general practitioner, the lesion did not resolve and the swelling was observed to grow bigger between these episodes. Clinical examination revealed an indurated, erythematous $8-9 \mathrm{~mm}$ ulcerative lesion in the middle of the dorsal aspect of the penile shaft. The patient had not been circumcised and had never reported a similar complaint from anywhere else in his body. Excisional biopsy was performed, and histology showed the classical findings of pilonidal sinus with hair shaft within. It is essential to highlight the fact that diagnosis was made post-operatively based on histopathological findings rather than on preoperative clinical assessment. In some cases diagnosis can be made before operating on the patient (Rao et al 2006). The patient had an uneventful recovery and his symptoms have since resolved completely.

\section{Discussion}

Pilonidal sinus was first described by Anderson (1847). It is a condition that affects hairy areas such as the natal cleft, axillae, perineum, finger web space in the hands of barbers, and amputation stumps (Saharay et al 1997). The pathogenesis of pilonidal sinus is controversial although it is agreed that it is acquired. The present view is that the large majority of pilonidal sinuses have an acquired pathogenesis. The initiating event appears to be follicular hyperkeratosis with plugging, leading to retention of follicular products (Lucas 1997). The rupture of a follicular unit or a cyst with 


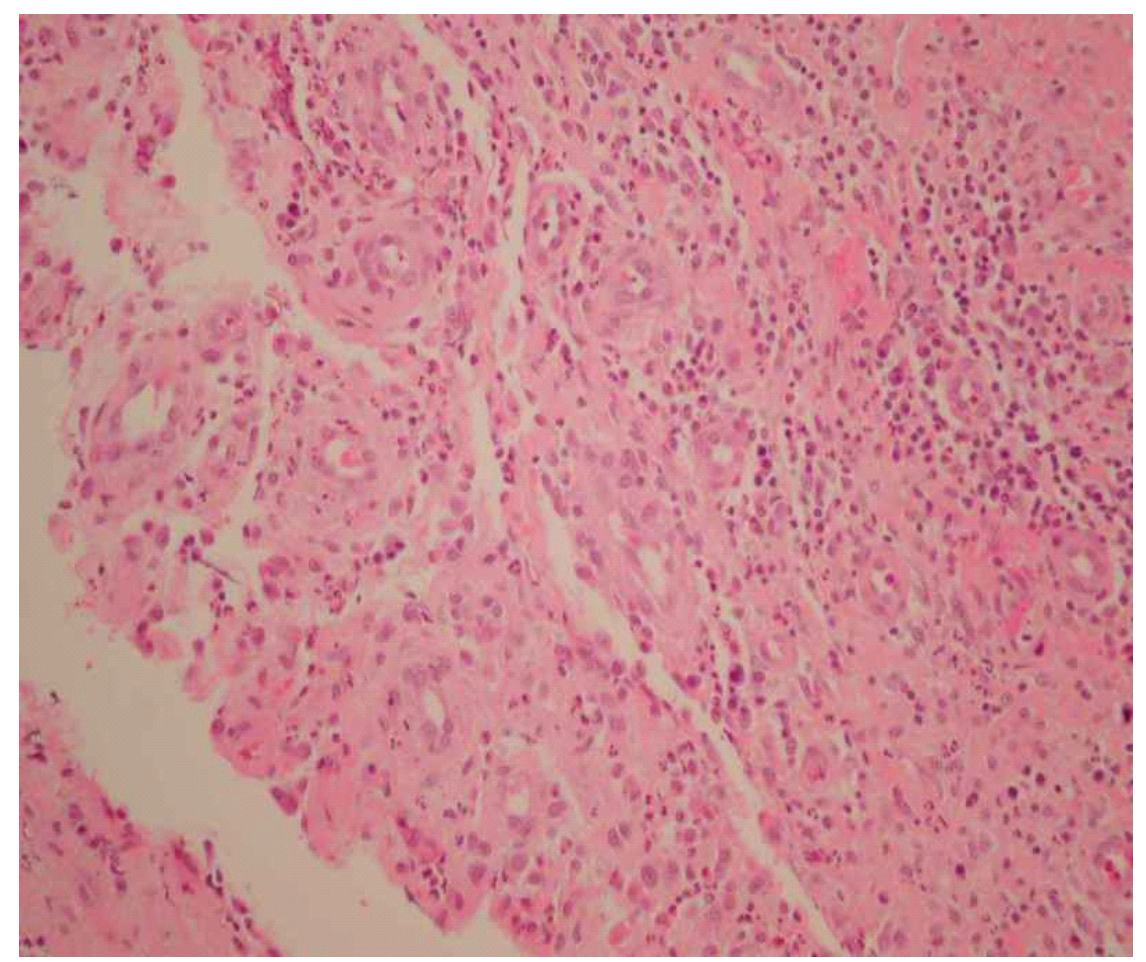

Figure I Chronic inflammatory lymphoid cell reaction.

secondary infection results in abscess formation. In some instances, sinuses formed to drain the abundant suppuration. The sinuses are lined by stratified squamous epithelium and inflammatory granulation tissue. Very often, numerous hair shafts penetrate into dermis and elicit foreign body giant cell reaction (Figure 1-3). The inflammatory reaction subsides after the pus is discharged. In some cases the opening onto the skin is absent and there is no secondary infection. There may be a pilonidal tract or cyst in these persons. The support for the acquired theory of the pilonidal sinus comes from their occurrence in situations such as the finger web space in the hands of barbers, and in amputation stumps. Therefore many

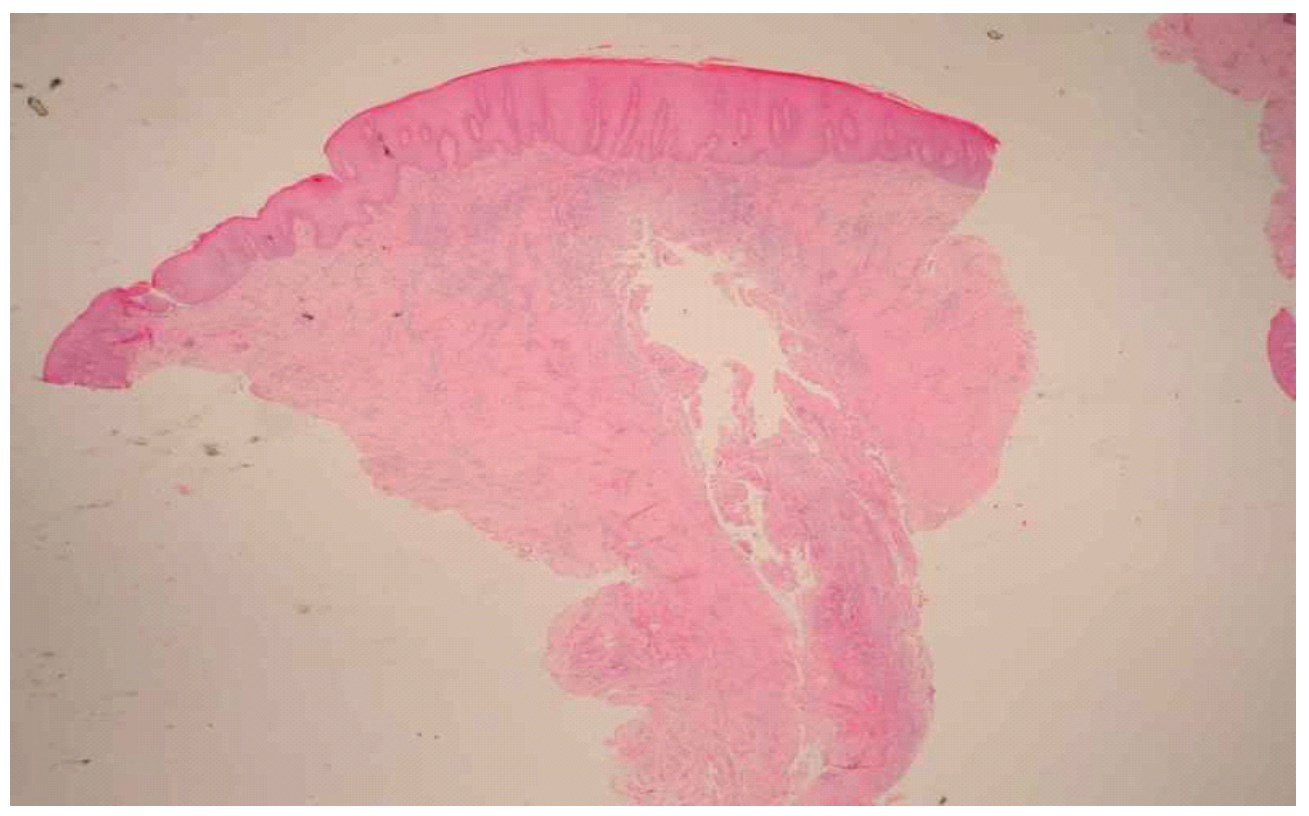

Figure 2 Slide showing the pilonidal sinus with the inflammatory reaction around the sinus. 


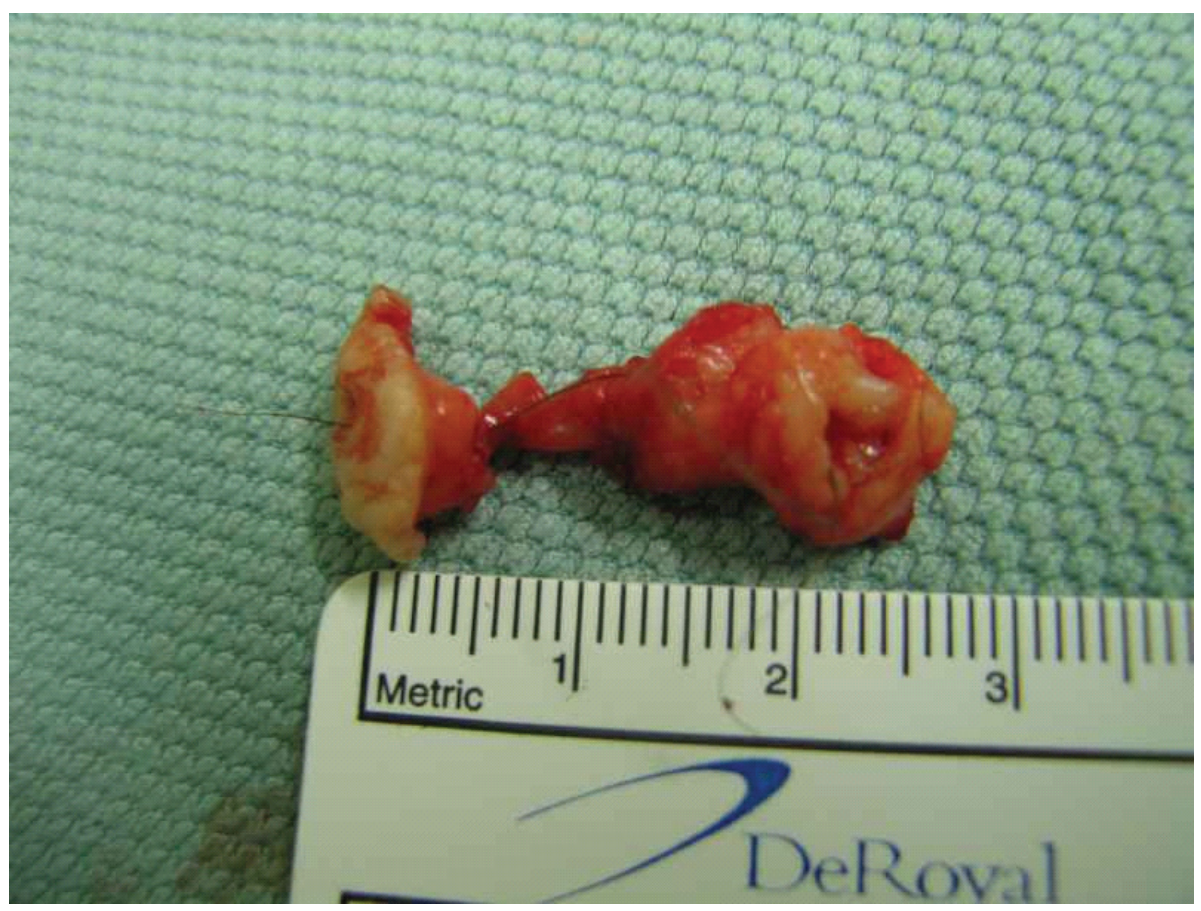

Figure 3 Gross specimen for the pilonidal sinus after excision which measures $26 \mathrm{~mm}$.

cases are acquired as a result of trauma from "jeep seat", "rough riding syndrome", and occupational physical injury (Val-Bernal et al 1999). The literature was reviewed and a few cases were reported worldwide (Val-Bernal et al 1999; Chikkamuniyappa et al 2004; Kalsi et al 2004; O'Kane et al 2004). The literature referred to penile pilonidal sinus with some other pathologies such as actinomycosis infection (ValBernal et al 1999; Chikkamuniyappa et al 2004) or erectile dysfunction (Kalsi et al 2004). Therefore, a good clinical assessment and bacteriological examination is essential to obtain better results.

In our case, we reported on a pilonidal sinus where diagnosis was made on histopathological findings with no evidence of associated bacterial infection or malignancy (Rao et al 2006). Our patient did not experience pilonidal sinuses problems anywhere else in his body. Our patient had full recovery and no symptoms since, his post-operative follow-up involved two out-patient visits at up to 12 weeks post-operation. The patient had no symptoms or recurrence up to that time, interval circumcision was deferred due to the patient's general health status and his mental disability.

\section{Disclosure}

The authors report no conflicts of interest in this work.

\section{References}

Anderson AW. 1847. Hair extracted from an ulcer. Boston Med Surg J, 36:76.

Chikkamuniyappa S, Scott RS, Furman J. 2004. Pilonidal sinus of the glans penis associated with actinomyces case reports and review of literature. Scientific World Journal, 4:908-12.

Kalsi JS, Arya M, Freeman A, et al. 2004. A pilonidal sinus on the penis presenting with erectile dysfunction, Scand J Uro Neph, 38:92-3.

Lucas S. 1997. Bacterial disease, In: Elder D, Elenitsas R, Jaworsky C, et al. (eds). Lever's histopathology of the skin. Phliadelphia: LippincottRaven Publishers, p. 457.

O'Kane HF, Duggan B, Mulholand C, et al. 2004. Pilonidal sinus of penis. Scientific World Journal, 4(Suppl 1):258-9.

Rao AR, Sharma M, Thyveetil M. 2006. An unusual site for pilonidal sinus. Int Urol Nephrol, 38(3-4):607-8

Saharay M, Farooqui A, Chappell M. 1997. An unusual lesion of the penis. Postgrad Med J, 73:179.

Val-Bernal JF, Azcarretazabal T, Garijo MF. 1999. Pilonidal sinus of the penis. A report of two cases, one of them associated with actinomycosis, $J$ Cutan Pathol, 26:155-8. 